\title{
Cervical Squamous Intraepithelial Neoplasia 1
}

National Cancer Institute

\section{Source}

National Cancer Institute. Cervical Squamous Intraepithelial Neoplasia 1. NCI Thesaurus.

Code C40199.

Cervical squamous intraepithelial neoplasia characterized by the presence of maturation in the upper two-thirds of the squamous epithelium and mild nuclear atypia which is present in all epithelial layers. Mitotic figures are present in the basal third of the epithelium. 